\title{
GESTÃO SUSTENTÁVEL DAS FLORESTAS PÚBLICAS NO BRASIL (LEI 11.284/06)
}

\author{
Diana Suzete Nunes da Silva ${ }^{1}$
}

\section{Luís Antônio Coimbra Borges ${ }^{2}$}

\section{Geiziana das Dores Nunes da Silva ${ }^{3}$}

RESUMO: O Brasil é conhecido como o país que possui a maior floresta tropical do mundo (516 milhões de hectares $(60,7 \%)$ de florestas naturais e plantadas). Com o tempo, a fronteira agropecuária avançou rapidamente ao longo de uma série de frentes pioneiras, estendendo-se adentro da floresta. A Lei de Gestão de Florestas Públicas (Lei №. 11.284/06) foi elaborada para orientar as pessoas sobre como explorar economicamente as florestas públicas, sendo uma conquista da sociedade brasileira. Objetiva-se no presente trabalho sintetizar informações relacionadas a essa forma de Gestão no Brasil e demonstrar a importância desse instrumento para o desenvolvimento florestal sustentável no país. Para tanto, serão descritos, sem a pretensão de exaurimento, conceitos específicos, a iniciar pela definição sobre florestas públicas e em seguida pela descrição do instrumento jurídico da concessão, disposto na legislação. Além disso, o contrato de concessão dessas florestas é um instrumento legal que viabiliza a exploração

${ }^{1}$ Engenheira Florestal, mestranda em Engenharia Florestal pela Universidade Federal de Lavras UFLA/MG. E-mail: disuzete.florestal@posgrad.ufla.br.

${ }_{2}$ Professor Doutor do Programa de Pós-Graduação Stricto Sensu em Ciências Florestais - UFLA. e-mail: luis.borges@dcf.ufla.br.

${ }^{3}$ Bacharel em Turismo, Pós-Graduanda em Gestão Pública no Instituto Superior de Pesquisa e PósGraduação - ISUP, desenvolve Projeto Social na Odebrecht Energia UHE Teles Pires - MT. e-mail: geizianasilva@oec.com.br. 
sustentável das florestas públicas, com o objetivo de atenuar o desmatamento ilegal, permitindo também a regularização da posse de comunidades locais tradicionais. Este artigo analisa sua atribuição jurídica, bem como trata de suas características procedimentais. Com a criação e aplicação da Lei surgiram novos órgãos e novas figuras institucionais. Embora seja cedo para colher os frutos dos processos de concessão, a ideia de unir forças entre governo, comunidades e o setor privado, parece ser o caminho para uma economia de base florestal sustentável e duradoura, de forma a garantir riquezas e prosperidade para as populações que conservam e utilizam as florestas.

Palavras-chave: Legislação ambiental. Concessão florestal. Manejo florestal.

\section{INTRODUÇÃO}

O Brasil tem mais da metade de sua área coberta por florestas. Este fato o torna conhecido como o país que possui a maior floresta tropical do mundo (BRASIL, 2009a). Seu território estende-se por mais de 851 milhões de hectares (IBGE, 2002). Sendo 516 milhões de hectares $(60,7 \%)$ de florestas naturais e plantadas (SFB, 2010) que garantem muitos produtos e serviços para a sociedade (alimentos, madeiras, remédios, entre outros), e encontram-se muitos tipos de plantas e animais que, na sua maioria, ainda são desconhecidos.

O histórico brasileiro de utilização predatória da terra inicia desde a colonização. A Coroa Portuguesa demonstrou preocupações com as questões ambientais no Brasil, ao criar as Ordenações Manuelitas que perdurou até 1603. A partir de 12 de dezembro de 1605, ocorre a Regulamentação do Pau Brasil, editado pelo El-rei. Regimento que pode ser caracterizado como a primeira espécie de concessão florestal.

A autorização produzida pelo Provedor mor de cada Capitania deveria ser registrada em livros com os nomes dos autorizados e o volume que poderia explorar na mata existente. Caso excedesse este volume o explorador seria punido com multa e confisco proporcional ao excesso da madeira, podendo até perder toda sua fazenda e a vida. 


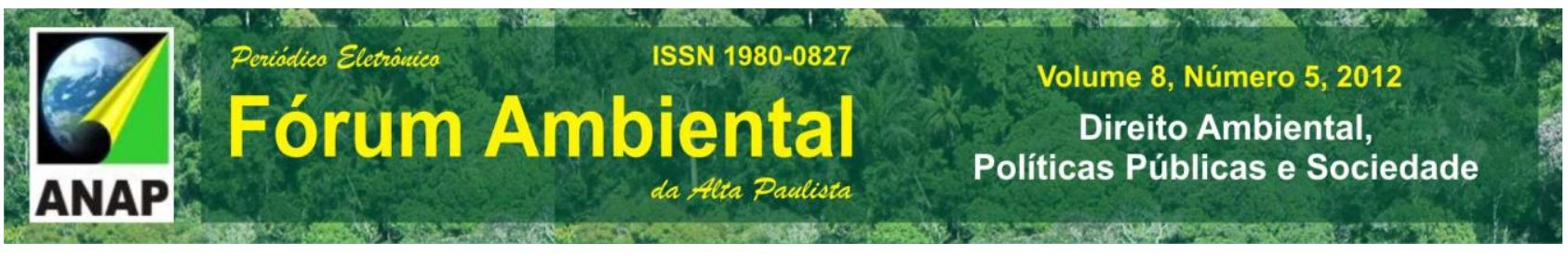

As áreas de Florestas Públicas foram criadas inicialmente como Parques Florestais, pelo Instituto Nacional do Pinho (INP), órgão responsável por administrá-las. Em 1967, com a criação do Instituto Brasileiro de Desenvolvimento Florestal (IBDF), os Parques Florestais, foram transformados em Florestas Nacionais (FLONAS), sendo administradas pelo novo órgão. O Código Florestal de 1934 continha uma seção sobre exploração de florestas de domínio público mediante concorrência pública, conditas na categoria de Floresta de Rendimento (CASTRO, 2008). No Código Florestal de 1965 (Lei 4.771) as Florestas de Rendimento passaram a ser classificadas como Florestas Nacionais, Estaduais e Municipais.

Em 1978 surge o termo Concessão para Florestas Públicas pela primeira vez no Congresso Florestal, em Manaus. A proposta foi rapidamente enterrada devido: a dificuldade da Superintendência do Desenvolvimento da Amazônia (SUDAM) estabelecer mais uma categoria de Unidade de Conservação federal; ao equívoco veiculado pela mídia com concessões para exploração de petróleo, em discussão, naquele período; e a enorme oferta de madeira na fronteira agropecuária dos eixos de expansão na Amazônia, na década de 1970 (CASTRO, 2008).

A região amazônica era vista como escape espacial para os conflitos sociais nãosolucionados. Novas terras na Amazônia foram colocadas à disposição, como a chamada "alternativa para a reforma agrária" (KOHLHEPP, 1979 citado por KOHLHEPP, 2002). Todavia, o slogan do governo, "Há terra para todos na Amazônia", deu impulso à migração de massa para o norte, tendo sido iniciada espontaneamente na segunda metade dos anos 1970 (KOHLHEPP, 1984, citado por KOHLHEPP, 2002). A fronteira agrícola avançou rapidamente ao longo de uma série de frentes pioneiras, estendendo-se adentro das florestas tropicais (KOHLHEPP, 2002).

Por causa disso, o aumento do desmatamento na Amazônia aconteceu de forma muito rápida, mas sem que a população pudesse se beneficiar da exploração dos recursos desta floresta. O Manejo Florestal que é baseado em técnicas apropriadas, surge como opção, pois permite que a comunidade possa gerar produtos e serviços sem degradar a floresta, ao mesmo tempo em que a regenera. $E$, para que se possa fazer o Manejo Florestal Sustentável e utilizar economicamente os recursos da floresta, é necessário obedecer duas regras básicas: 1) ter certeza da posse da terra, isto é, a 
garantia de que a terra é regularizada e que seu uso será respeitado ao longo do tempo; 2) fazer o planejamento para saber qual a área de floresta que se tem para manejar e os resultados que se quer obter, pois desta forma, num ciclo de 25 a 30 anos, será possível ter a floresta regenerada e com a capacidade de produção mantida (BRASIL, 2009a).

Até 2006, não existia uma lei para orientar as pessoas sobre como explorar economicamente uma floresta pública. Mesmo aquelas que já estavam destinadas ao uso sustentável (Florestas Nacionais), também tinham carência de uma legislação. A Lei de Gestão de Florestas Públicas (Lei no. 11.284/06) foi elaborada, sendo uma conquista da sociedade brasileira. Resultado de uma grande mobilização social que envolveu 14 audiências púbicas e a participação de mais de 1200 instituições, dentre elas: governo federal, estados, organizações não-governamentais (ONGs), setor empresarial, movimentos sociais, associações de trabalhadores, universidades e centros de pesquisa.

Em vista do exposto, o presente trabalho visa sintetizar informações relacionadas à Gestão de Florestas Públicas no Brasil (Lei 11.284/06). Para tanto, serão descritos, sem a pretensão de exaurimento, conceitos específicos, a iniciar pela definição sobre florestas públicas e em seguida pela descrição do instrumento jurídico da concessão, disposto na legislação, o qual permite e direciona a exploração sustentável dos produtos e serviços advindos das formações florestais, de acordo com a norma ora em destaque.

\section{GESTÃO DE FLORESTAS PÚBLICAS (LEI №. 11.284/06)}

As concessões florestais em alguns países são aplicadas de forma mais permissiva, concedendo o direito de posse das terras aos concessionários, como o utilizado pelo Chile. Em outros casos, o concessionário tem apenas o direito de explorar ou manejar a área concedida nos termos do contrato, ou comprar madeira explorada pelo estado como acontece na Tanzânia (BARRETO E VERÍSSIMO, 2002 citados por CASTRO, 2008).

Em muitos modelos de concessão, a variável ambiental nem sempre faz parte dos elementos acordados entre as partes e tal realidade favorece a exploração de forma 
irracional das florestas, exaurindo os recursos, como está acontecendo na Ásia e migrando para outras regiões no mundo com estoques maiores (FERRAZ E SEROA DA MOTTA, 2002, citados por CASTRO, 2008).

Boa parte das críticas às concessões florestais se baseia no fato de que, em países como Peru, Bolívia, Indonésia e Camarões esse instrumento não tem sido capaz de garantir boas práticas de produção florestal, ou ainda pior, resulta em uma chancela governamental as práticas predatórias do setor florestal (VOIVODIC, 2009).

Aprovada pelo Congresso Nacional e pelo Presidente da República em 2 de março de 2006, a Lei №. 11.284 dispõem em seu Art. 1ํ sobre a Gestão de Florestas Públicas para produção sustentável, institui o Serviço Florestal Brasileiro (SFB), na estrutura do Ministério do Meio Ambiente (MMA), e cria o Fundo Nacional de Desenvolvimento Florestal (FNDF).

Essa Lei possui como princípios, em seu Art. 2:

I - a proteção dos ecossistemas e valores culturais associados;

II - o uso eficiente e racional das florestas;

III - o respeito ao direito da população, de acesso às florestas públicas;

IV - a agregação de valor aos produtos e serviços da floresta, à utilização e à capacitação de empreendedores locais e da mão-de-obra regional;

V - o acesso livre de qualquer indivíduo às informações referentes à gestão de florestas públicas;

VI - a promoção e difusão da pesquisa florestal, faunística e edáfica, relacionada à conservação, à recuperação e ao uso sustentável das florestas;

VII - o fomento ao conhecimento e a promoção da conscientização da população sobre a importância da conservação, da recuperação e do manejo sustentável dos recursos florestais;

VIII - a garantia de condições estáveis e seguras que estimulem investimentos de longo prazo no manejo, na conservação e na recuperação das florestas.

Em seu Art. $3^{\circ}$, consideram-se:

I - florestas públicas: florestas, naturais ou plantadas, localizadas nos diversos biomas brasileiros, em bens sob o domínio da União, dos Estados, dos Municípios, do Distrito Federal ou das entidades da administração indireta; 
II - recursos florestais: elementos ou características de determinada floresta, potencial ou efetivamente geradores de produtos ou serviços florestais;

III - produtos florestais: produtos madeireiros e não madeireiros gerados pelo manejo florestal sustentável;

IV - serviços florestais: turismo e outras ações ou benefícios decorrentes do manejo e conservação da floresta, não caracterizados como produtos florestais;

VI - manejo florestal sustentável: administração da floresta para a obtenção de benefícios econômicos, sociais e ambientais, respeitando-se os mecanismos de sustentação do ecossistema objeto do manejo e considerando-se, cumulativa ou alternativamente, a utilização de múltiplas espécies madeireiras, de múltiplos produtos e subprodutos não madeireiros, bem como a utilização de outros bens e serviços de natureza florestal.

\subsection{MODALIDADES DE GESTÃO DE FLORESTAS}

\subsubsection{Gestão direta governamental}

Art. 5ㅇ Poder Público poderá exercer diretamente a gestão de florestas nacionais, estaduais e municipais criadas, sendo-lhe facultado, para execução de atividades subsidiárias, firmar convênios, termos de parceria, contratos ou instrumentos similares com terceiros, observados os procedimentos licitatórios e demais exigências legais pertinentes.

$\S 1$ Duração limitada a dez anos.

$\S$ 2ํNas licitações para as contratações, além do preço, poderá ser considerado o critério da melhor técnica.

\subsubsection{Destinação às comunidades locais}


Art. 6ำ Antes da realização das concessões florestais, as florestas públicas ocupadas ou utilizadas por comunidades locais serão identificadas para a destinação, pelos órgãos competentes, por meio de:

I - criação de reservas extrativistas e reservas de desenvolvimento sustentável;

II - concessão de uso, por meio de projetos de assentamento florestal, de desenvolvimento sustentável, agroextrativistas ou outros similares;

III - outras formas previstas em lei.

$\S 1^{\circ}$ A destinação de que trata o caput deste artigo será feita de forma não onerosa para o beneficiário e efetuada em ato administrativo próprio, conforme previsto em legislação específica.

$\S 2^{\circ}$ Sem prejuízo das formas de destinação previstas no caput deste artigo, as comunidades locais poderão participar das licitações previstas, por meio de associações comunitárias, cooperativas ou outras pessoas jurídicas admitidas em lei.

\subsubsection{Gestão indireta ou concessão florestal}

O uso da floresta é feito pelo setor privado. Quem faz a exploração tem que pagar anualmente pelos recursos florestais que são retirados.

Art. 8ํ A publicação do edital de licitação de cada lote de concessão florestal deverá ser precedida de audiência pública, por região, realizada pelo órgão gestor, nos termos do regulamento, sem prejuízo de outras formas de consulta pública.

Licitação é um tipo de concorrência para ver quem oferece as melhores vantagens para o uso da floresta. Quem oferecer ao mesmo tempo a melhor proposta técnica - considerando aspectos ambientais, sociais, de eficiência e de agregação de valor -, assim como o melhor preço, será o selecionado. Pequenas, médias e grandes empresas, cooperativas e comunidades podem participar das licitações (BRASIL, 2009a).

Assim, é importante observar que: 1) nos três tipos de gestão é possível explorar diferentes produtos como: madeira, óleos essenciais, frutos, sementes, etc. A floresta também pode ser utilizada para a produção de outros bens e serviços, como turismo, lazer, pesquisa científica, etc; 2) Podemos ter florestas públicas tanto naturais quanto 
plantadas, tanto na Amazônia como em outras regiões do país; 3) A floresta e a área continuam sendo públicas.

Segundo os Art. $16^{\circ}$ e $17^{\circ}$ é vedada a outorga de acesso aos recursos genéticos, fauna, recursos minerais, recursos hídricos, o carbono, nem os produtos usados pelas comunidades locais para sua subsistência.

\subsection{SERVIÇO FLORESTAL BRASILEIRO (SFB)}

A principal mudança foi a criação do Serviço Florestal Brasileiro, que gerencia as florestas públicas federais, planeja, propõem formas de uso e realiza o processo de concessão florestal. Além disso, cada estado ou cada município pode gerenciar suas florestas públicas. No Estado do Acre a instituição responsável pelo processo de concessão florestal é a Secretaria de Desenvolvimento Florestal, da Indústria, do Comércio e dos Serviços Sustentáveis (SEDENS); no Amazonas é a Agência de Desenvolvimento Sustentável (ADS); e no Pará o Instituto de Desenvolvimento Florestal (Ideflor). A Gestão Florestal Federal ficou estruturada conforme a Figura 1.

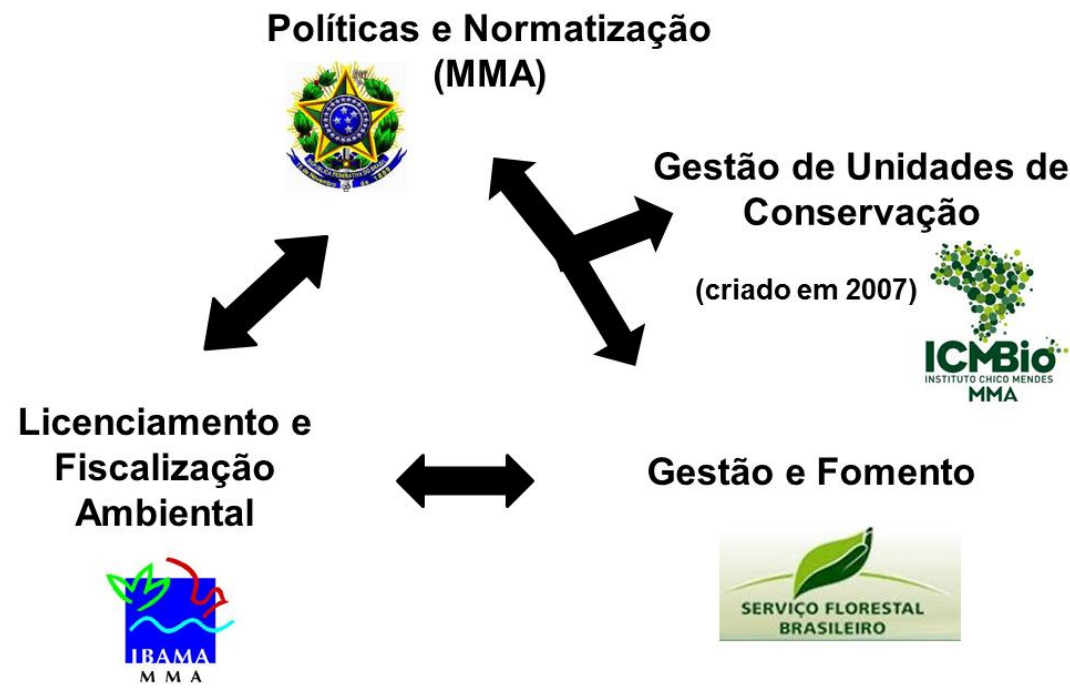

Figura 1. Gestão Florestal Federal (Fonte: adaptado de www.florestal.gov.br).

O Serviço Florestal Brasileiro tem sua sede em Brasília e em mais quatro unidades regionais: na região da BR 163 no Pará, com sede em Santarém; na região do 
Purus-Madeira, com sede em Porto Velho - Rondônia; na região Nordeste, com sede em Natal - Rio Grande do Norte; e na região Sul/Sudeste, com sede em Colombo - Paraná.

O Serviço Florestal Brasileiro, em parceria com outros órgãos governamentais, trabalha com comunidades e empresas, aplicando nas regiões acima, os conhecimentos sobre manejo florestal, que permite o uso sustentável das florestas e agrega valor ao que é produzido no próprio local (BRASIL, 2009b).

\subsection{CADASTRO NACIONAL DE FLORESTAS PÚBLICAS (CNFP)}

O Cadastro Nacional de Florestas Públicas foi criado pela Lei de Gestão de Florestas Públicas e regulamentado pelo Decreto ํo 6.063/2007, e pela Resolução do SFB no 2/2007, sendo integrado pelo Cadastro-Geral de Florestas Públicas da União e pelos Cadastros de Florestas Públicas dos Estados, do Distrito Federal e dos Municípios (Art. 14ํ).

Armazena em um banco de dados georreferenciado informações governamentais sobre florestas públicas destinadas à conservação e às comunidades, bem como sobre aquelas ainda sem destinação (SFB, 2010). Contribuem com informações para o Cadastro órgãos gestores de terras públicas federais, como: Instituto Chico Mendes de Conservação da Biodiversidade (ICMBio/Ministério do Meio Ambiente), Fundação Nacional do Índio (Funai/Ministério da Justiça), Instituto Nacional de Colonização e Reforma Agrária (Incra/Ministério do Desenvolvimento Agrário) e Ministério da Defesa, assim como: órgãos estaduais de gestão florestal, meio ambiente e institutos de terras.

Em 2011, o Serviço Florestal Brasileiro realizou a quarta atualização dos dados e das informações do CNFP, totalizando 297 milhões de ha (BRASIL, 2012). A forma como as florestas públicas são ocupadas pode ser bem diferente, como pode ser observado na figura 2, sendo 222 milhões de ha de florestas públicas federais e 75 milhões de ha de florestas públicas estaduais. 


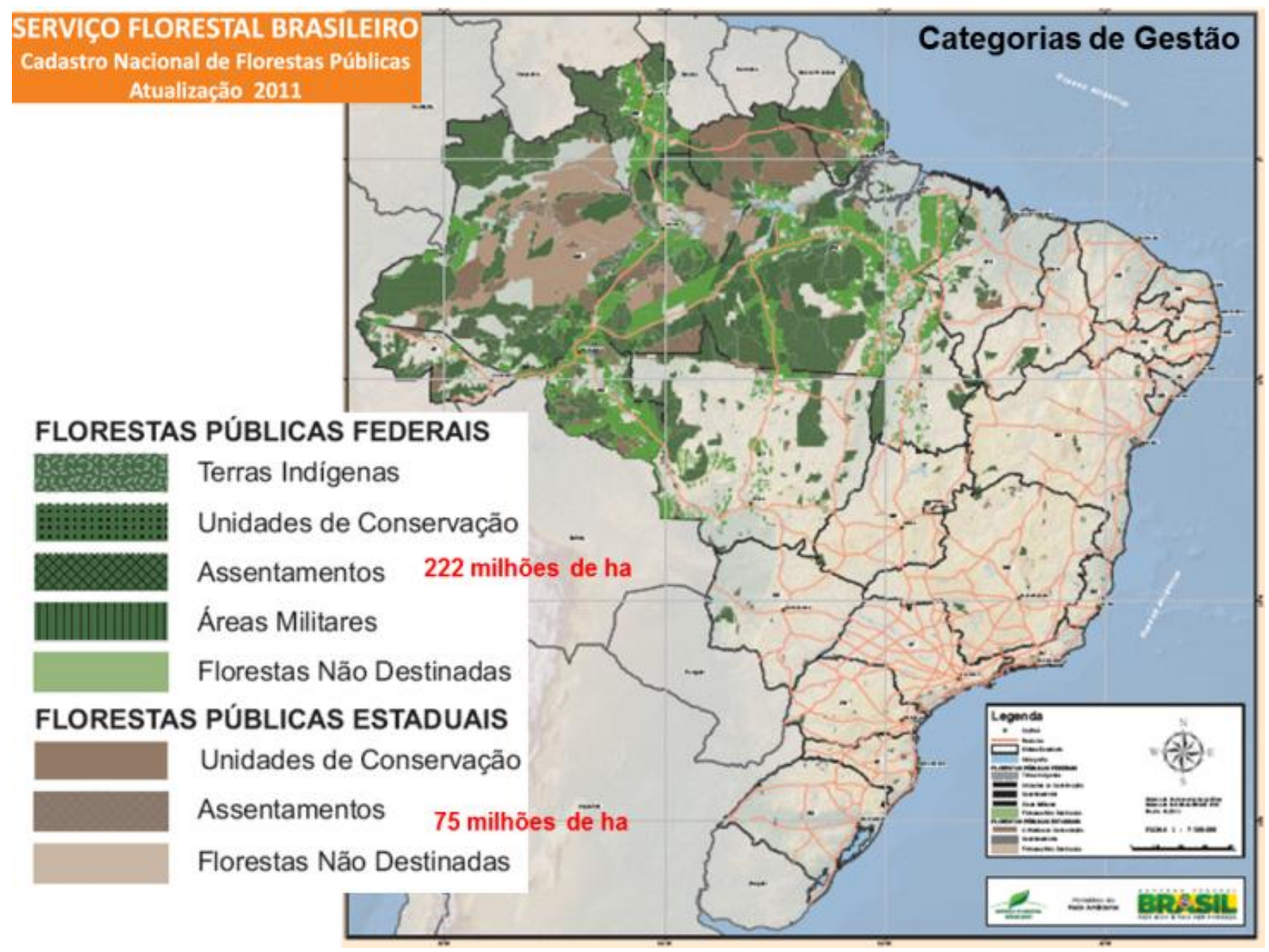

Figura 2. Categorias de Gestão das Florestas Públicas Brasileiras (Fonte: adaptado de www.florestal.gov.br).

Essa atualização acrescentou cerca de 12 milhões de hectares de florestas públicas, em relação ao ano base de 2010. Esse acréscimo decorreu, principalmente, da inclusão de 10.436.230 ha de novas florestas públicas federais, dos quais 4.736 .549 ha são florestas com destinação específica (maior contribuição das áreas militares) e as demais correspondem a florestas públicas não destinadas. Ademais, foram acrescentados 1.832.637 ha de florestas estaduais não destinadas, principalmente no Pará (BRASIL, 2012).

Entre 2007 e 2011, foram cadastrados aproximadamente 300 milhões de hectares de florestas públicas no Brasil, equivalente a cerca de 35\% do território brasileiro e a aproximadamente $57 \%$ das florestas brasileiras (Figura 3). E ao se analisar a localização 
nos biomas, verifica-se que 92\% está na Amazônia, conforme o quadro 1 que segue abaixo. Destas, 43,29\% estão localizadas no Amazonas e 87,87\% na região Norte.

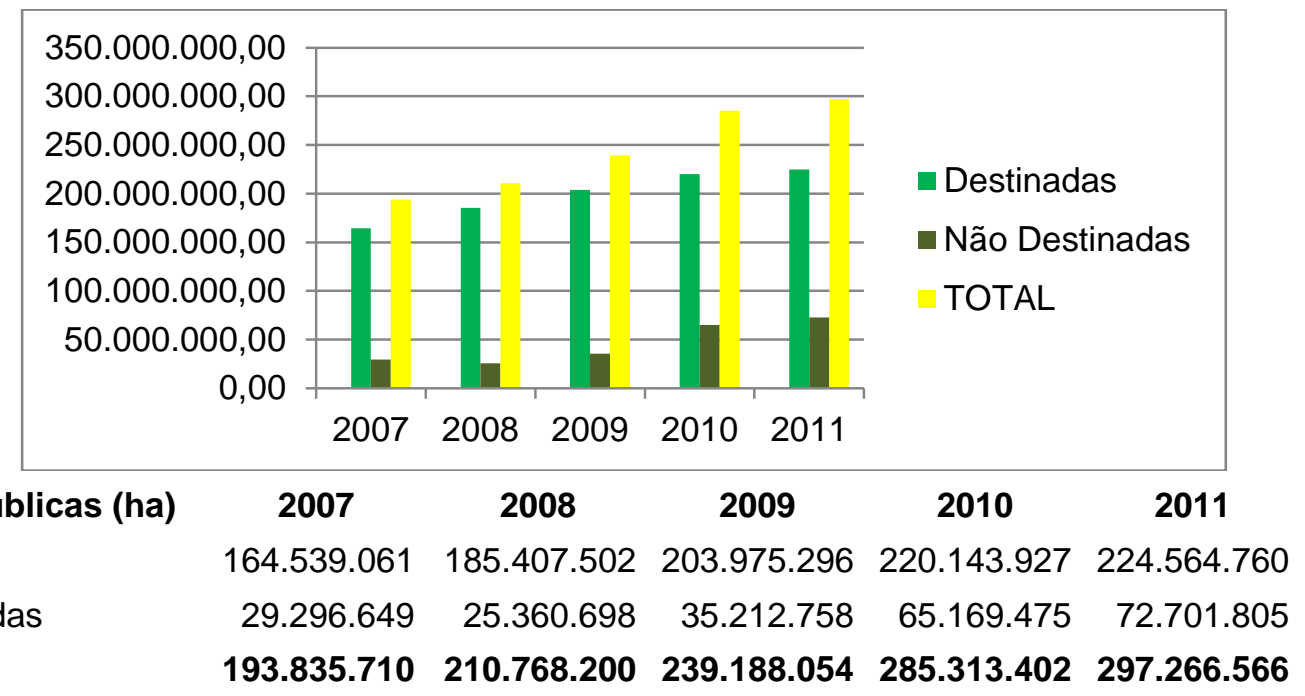

Figura 3. Evolução do Cadastro Nacional de Florestas Públicas no Brasil (Fonte: adaptado de www.florestal.gov.br).

Quadro 1. Localização das florestas públicas do Brasil nos diferentes biomas.

\begin{tabular}{ccc}
\hline Biomas & Área (ha) & $\%$ \\
\hline Amazônia & 272.760 .987 & 92 \\
Cerrado & 17.294 .941 & 6 \\
Mata Atlântica & 3.093 .451 & 1,15 \\
Caatinga & 1.253 .627 & 0,5 \\
Pantanal & 737.374 & 0,25 \\
Pampa & 229.367 & 0,1 \\
\hline Total & 297.266 .565 & 100
\end{tabular}

Fonte: adaptado de www.florestal.gov.br (2012).

\subsection{CONCESSÕES FLORESTAIS}

As florestas públicas que não foram destinadas às comunidades locais, o Poder Público pode conceder a uma pessoa jurídica o direito de manejar. Neste caso, esta empresa ou associação deve pagar ao Poder Público por este uso (BRASIL, 2009a). De 
acordo com o Art. 19² da Lei №. 11.284/2006, as empresas devem ser brasileiras, com sede e administração no Brasil, com toda situação fiscal regularizada e sem ter causado danos ambientais.

Conforme o Art. 26ํㅡ, ganha o processo de concessão quem oferecer a melhor proposta técnica e o maior preço pelos produtos. Considera-se aquela proposta que se compromete a: causar o menor impacto ambiental; gerar maior rendimento e vantagens para as pessoas envolvidas; garantir o melhor uso dos recursos florestais; e garantir a maior agregação de valor. E segundo o Art. $27^{\circ}$ cada área só pode ter um ganhador da concessão. Na Figura 4 observam-se as fases e etapas do processo de concessão florestal.

Fase Pré-Edital Inclui todas etapas até a publicação do edital de licitação

\section{Cadastro das Florestas Públicas}

Plano Anual de Outorga Florestal

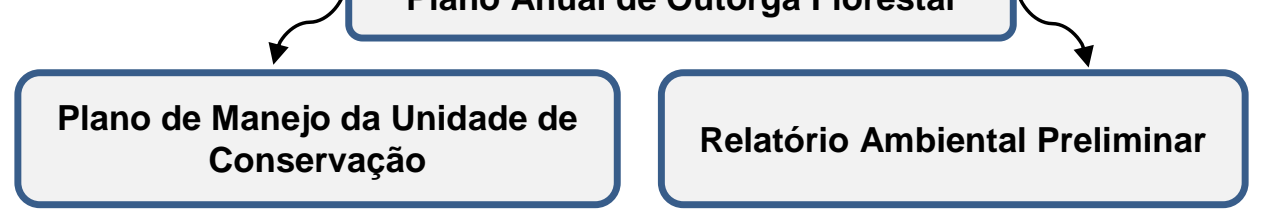

Publicação do Pré-Edital

Consulta e Audiências Públicas

Publicação do Edital

Fase Seleção e Contratação Inclui todas etapas até a assinatura do contrato de concessão florestal
Habilitação

Julgamento das propostas

Assinatura de Contrato

Elaboração do PMFS

Monitoramento, Fiscalização e Auditorias
Fase Execução

Inclui as atividades relacionadas a implantação do manejo florestal e ao monitoramento, fiscalização e auditorias
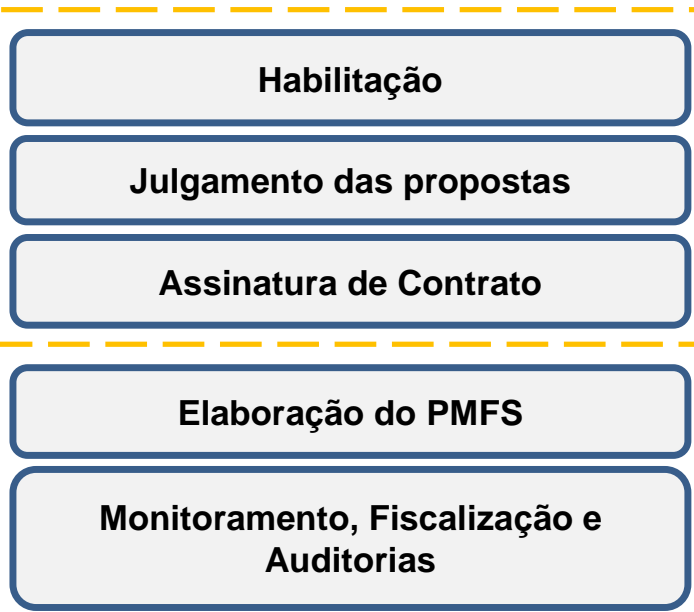

Figura 4. Fases e etapas do processo de concessão florestal (Fonte: adaptado de BRASIL, 2009a). 
Aquele que recebeu a concessão deverá pagar, pelo menos, um preço mínimo definido pelo Poder Público (Art. 36º, inciso II), que corresponde à quantidade de produtos ou serviços explorados ou do faturamento a partir da venda desses produtos. Além deste pagamento, será determinado um valor fixo mínimo, anual, que o concessionário deverá pagar ao Poder Público, independentemente da produção obtida durante o ano (Art. 36², parágrafos $3^{\circ}, 4^{\circ}$ e $\left.5^{\circ}\right)$.

Para receber os recursos, os estados e municípios, devem abrir contas bancárias específicas para este fim, e aplicar este valor, obrigatoriamente, para apoiar e promover a utilização sustentável dos recursos florestais (Art. 40). Os conselhos de meio ambiente devem acompanhar o planejamento e utilização destes recursos.

A Concessão florestal foi elaborada para ser um instrumento de desenvolvimento sustentável. No local onde acontece, a floresta será utilizada através do manejo sustentável, gerando empregos, recolhendo impostos e beneficiando a população local (BALIEIRO et al., 2010). É sempre muito importante que a população acompanhe e participe do processo.

Os recursos do Fundo Nacional de Desenvolvimento Florestal serão aplicados (Art. 41, § $1^{\circ}$ ): na pesquisa e desenvolvimento de novas tecnologias em manejo florestal; assistência técnica e extensão florestal; recuperação de áreas degradadas com espécies nativas; aproveitamento econômico racional e sustentável dos recursos florestais; controle e fiscalização das atividades florestais e desmatamentos; capacitação em manejo florestal e formação de agentes multiplicadores em atividades florestais; educação ambiental; proteção ao meio ambiente e conservação dos recursos naturais.

Estão previstas no Art. $42^{\circ}$, auditorias independentes e periódicas, com prazo máximo de 03 anos, sendo realizada por entidade credenciada pelo Instituto Nacional de Metrologia, Qualidade e Tecnologia (INMETRO) e reconhecida pelo SFB. Quando for identificado algum prejuízo ao meio ambiente, os concessionários serão punidos nas esferas administrativa, civil e penal. Inclusive com a possibilidade de suspensão do contrato e a utilização do valor depositado como garantia, como uma forma de compensar os danos (Art. 45).

Até 2010, o SFB assinou contratos para concessão florestal em duas florestas nacionais (Flonas): Floresta Nacional do Jamari (RO); e Floresta Nacional de Saracá- 
Taquera (PA). No total, foram disponibilizados 144,8 mil hectares de floresta que serão manejadas de forma sustentável por 05 empresas durante 40 anos. As condições a serem cumpridas foram apresentadas e discutidas em audiências públicas nos municípios vizinhos às áreas que foram concedidas.

A Flona do Jamari (RO), localizada entre os municípios de Cujubim, Porto Velho, Ariquemes e Itapuã do Oeste, foi criada em 25 de setembro de 1984, possui uma área aproximada de 220 mil hectares, dos quais 96 mil foram destinados para concessão florestal. Sendo a primeira concessão florestal do Brasil. O edital ficou aberto por 45 dias e recebeu 19 propostas de 14 empresas dos estados de Rondônia, São Paulo, Bahia e Pará. Três empresas venceram a licitação (SFB, 2012). A empresa Madeflona Industrial Madeireira maneja a Unidade de Manejo Florestal I (UMF I), com 17 mil hectares. A empresa Sakura Indústria e Comércio de Madeiras ganhou a licitação para a UMFII, com 32,9 mil hectares. A empresa Amata venceu para a UMF III, com 46 mil hectares. Empresas de Rondônia manejam as UMFs 1 e 2.

Podem explorar (além da madeira): material lenhoso residual de exploração, PFNMs (folhas, raízes, cascas, frutos, sementes, óleos, látex e resinas) e serviços de hospedagem, esportes de aventura e visita e observação da natureza. O potencial de produção anual das três UMF de Jamari é da ordem de 82 mil metros cúbicos de madeira em toras, com retorno estimado aos cofres públicos de $\mathrm{R} \$ 3.8$ milhões por ano; criação de 372 empregos diretos, sendo a maioria formada por mão de obra local (BRASIL, 2009b). As comunidades continuarão a ter acesso aos recursos florestais tradicionalmente usados para a sua subsistência: o açaí, a castanha do Brasil e a copaíba.

\section{CONSIDERAÇÕES FINAIS}

A Lei de Gestão de Florestas Públicas foi criada com o intuito de definir procedimentos técnicos para a exploração da floresta e ao mesmo tempo conservá-la. Com a criação e aplicação da Lei surgiram novos órgãos e novas figuras institucionais. 


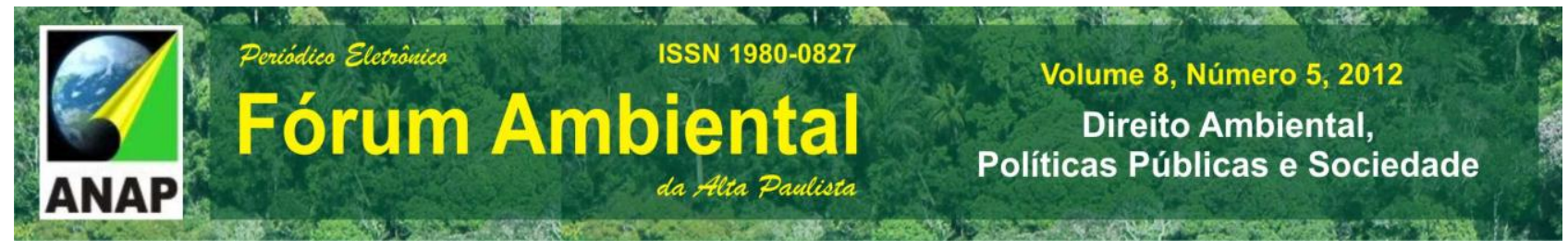

Embora seja cedo para colher os frutos dos processos de concessão, a ideia de unir forças entre governo, comunidades e o setor privado, parece ser o caminho para uma economia de base florestal sustentável e duradoura, de forma a garantir riquezas e prosperidade para as populações que conservam e utilizam as florestas.

Alguns desafios precisam ser superados como: regularização da situação fundiária no país; estabelecimento de parcerias entre comunidade(s), organizações e poder público (por exemplo, para a obtenção de crédito, assistência técnica para a atividade florestal e capacitação de mão de obra); além de estruturação e suporte aos órgãos ambientais (devido a atual carência na qualidade da infra-estrutura e déficit o quadro de servidores).

Contudo, o presente artigo destaca a importante contribuição das florestas públicas para o desenvolvimento nacional, de forma a evitar que as questões sociais e ambientais sejam desrespeitadas.

\section{REFERÊNCIAS}

BALIEIRO, M. R.; ESPADA, A. L. V.; NOGUEIRA, O.; PALMIERI, R.; LENTINI, M. As Concessões de Florestas Públicas na Amazônia Brasileira: um manual para pequenos e médios produtores florestais. $2^{\underline{a}}$ ed. Piracicaba: Imaflora, SP; Belém: IFT, PA, 2010.

BRASIL. Ministério do Meio Ambiente. Serviço Florestal Brasileiro. Gestão de Florestas Públicas e Comunidades. Brasília: MMA/SFB, 2009a.

BRASIL. Ministério do Meio Ambiente. Serviço Florestal Brasileiro. Gestão Florestal para a Produção Sustentável de Bens e Serviços no Brasil. Brasília: MMA/SFB, 2009b.

BRASIL. Ministério do Meio Ambiente. Serviço Florestal Brasileiro. Gestão de Florestas Públicas - Relatório 2011. Brasília: MMA/SFB, 2012.

CASTRO, Renata Medrado de. Concessão florestal no Brasil: primeira experiência federal. 2008. 33p. Monografia (Engenharia Florestal) - Universidade Federal Rural do Rio de Janeiro, Seropédica.

DECRETO № 6.063, DE 20 DE MARÇO DE 2007. Regulamenta, no âmbito federal, dispositivos da Lei no 11.284, de 2 de março de 2006, que dispõe sobre a gestão de florestas públicas para a produção sustentável, e dá outras providências. Disponível em: < 
http://www.planalto.gov.br/ccivil_03/_Ato2007-2010/2007/Decreto/D6063.htm>. Acesso em: 15 abr. 2012.

IBGE. Resolução № 05, de 10 de outubro de 2002. Disponível em: <http://www.ibge.gov.br/home/geociencias/cartografia/default_territ_area.shtm.>. Acesso em: 18 de abr. 2012.

KOHLHEPP, Gerd. Conflitos de interesse no ordenamento territorial da Amazônia brasileira. Estudos Avançados. São Paulo, v. 16, n. 45, p. 37-61, 2002.

LEI № 11.284, DE 02 DE MARÇO DE 2006. Dispõe sobre a gestão de florestas públicas para a produção sustentável; institui, na estrutura do Ministério do Meio Ambiente, o Serviço Florestal Brasileiro - SFB; cria o Fundo Nacional de Desenvolvimento Florestal FNDF. Disponível em:<http://www.planalto.gov.br/ccivil_03/_ato20042006/2006/lei//11284.htm>. Acesso em: 20 mar. 2012.

RESOLUÇÃO DO SFB № 2, DE 6 JULHO DE 2007. Regulamenta o Cadastro Nacional de Florestas Públicas, define os tipos de vegetação e as formações de cobertura florestal, para fins de identificação das florestas públicas federais, e dá outras providências.

Disponível em: < http://www.mp.rs.gov.br/ambiente/legislacao/id4880.htm?impressao=1 > . Acesso em: 15 abr. 2012.

Serviço Florestal Brasileiro. Disponível em: <www.florestal.gov.br>. Acesso em: 15 abr. 2012.

Serviço Florestal Brasileiro. Florestas do Brasil em resumo - 2010: dados de 20052010. Serviço Florestal Brasileiro. - Brasília: SFB, 2010.

VOIVODIC, Maurício de Almeida. Concessões florestais e o papel da certificação. Disponível em: http://www.acaoverde.org.br/v2/mostra.php?noticia=643. Acesso em: 10 maio 2012. 